\section{Birth cohort differences in physical functioning levels among elderly Brazilians: findings from the Bambuí Cohort Study of Aging (1997-2008)}

\author{
Diferenças de coorte por nascimento na função \\ física em uma população brasileira de idosos \\ mais velhos: Estudo de Coorte de Idosos \\ de Bambuí (1997-2008)
}

Cesar Messias de Oliveira 1

Maria Fernanda Lima-Costa 2

\section{Introduction}

The aim of this study was to investigate the cohort differences in physical functioning levels among the older (cohort members born in 1916-1926 and in 1927-1937) participants of the Bambui Cohort Study of Aging. The data came from participants aged 71-81 who took part at baseline in 1997 ( $n=$ 491) and in the 11th wave in $2008(n=620)$. The physical functioning variables included the following self-reported measures: activities of daily living, the instrumental activities of daily living and mobility. Poisson regression analyses were used to investigate the cohort year differences in physical functioning levels. Overall, the young cohort (2008) showed better levels of physical functioning compared to the older cohort (1997) across all three measures of physical functioning used.

Aged; Activities of Daily Living; Aging; Cohor Studies
Brazil is going through rapid demographic and health transitions which affect the elderly.

The Brazilian population is ageing rapidly. In the past decade, the number of Brazilians aged 60 and older increased 2.5 times more $(36 \%)$ than the younger age groups (14\%) (Instituto Brasileiro de Geografia e Estatística. Censo Demográfico 2000. http://www.ibge.gov.br). However, very little is known about the long term trends regarding physical functioning among older Brazilians 1 .

As the numbers of elderly people in Brazil are increasing, medical care and public health systems need to overcome the challenge of how to target their resources to best preserve the health of the elderly. From a public health point of view, as well as for the people themselves, it is essential to identify factors that play a part in active and healthy aging. Healthy aging consists of optimising life expectancy while at the same time minimising psychological, physical, and social morbidity 2. Functional capacity is one of the most important indicators of health status in the elderly population and it is also closely related to quality of life. Incapability in performing everyday activities independently and the resultant loss of personal autonomy are undesirable consequences of functional impairment at the individual level. At the population level, impaired functioning is associated with increased mortality $3,4,5,6$ and use of health services 7,8 . 
Physical function is a person's ability to perform normal physical activities of daily living (ADL). Disability occurs when a person has problems with physical function 9 , and it has enormous societal and personal implications. Mobility is also critical to maintaining independence and social interaction in the later years of life and is an essential aspect of quality of life. Persons with poor lower extremity function, slow gait speed, and particularly those with walking disability, are at higher risk of chronic disease, hospitalization, and death than their peers who walk normally 10,11 .

In general, the ADL scale describes activities essential for self-care like bathing, dressing and feeding. It includes the most basic activities involved in everyday independent functioning. The instrumental activities of daily living (IADL) scale describes activities necessary for adaptation to the environment and places an emphasis on community activities like shopping, cooking, transportation and housekeeping. The activities of IADL are more cognitively influenced 12 .

Studies conducted in developed countries have reported different trends regarding physical functioning levels among older people. Findings from a meta-analysis including studies from the USA showed a decline in the prevalence of poor physical functioning measured by the ADLand/or IADL indexes during the 1990s ${ }^{13}$. More recently, a large study was carried out to assess ADL trends in the countries from the Organization for Economic Cooperation and Development (OECD). Out of 12 countries, only five showed a decline in the prevalence of poor functioning (Denmark, Finland, Italy, Holland and the USA). In three countries (Belgium, Japan and Sweden) there was an increase and in two (Australia and Canada) the prevalence remained stable. In France and the United Kingdom, findings from different surveys showed discrepancies ${ }^{14}$. Furthermore, some studies demonstrated an improvement in physical functioning only according to IADLs but not according to ADLs particularly among the very oldest 13 .

In Brazil, very little is known about trends in physical functioning among the elderly. A recent work based on data from the Brazilian National Household Survey (PNAD) between 1998 and 2003 showed that the prevalence of ADLs (difficulty in showering, eating and using the toilet) remained stable 15 . However, because the three ADL activities mentioned above were grouped in the same question it was not possible to assess each activity separately. In addition, the PNAD questionnaire did not include IADL questions.

The Bambuí Cohort Study of Aging has detailed information regarding physical function- ing using ADLs, IADLs and mobility questions. Therefore, we have used data from this cohort study in the present work to explore the cohort differences regarding physical functioning levels at baseline (older cohort, 1997) and in 2008 (younger cohort) among older persons who took part in this long term Brazilian cohort study.

\section{Methodology}

\section{Design, setting and participants}

The data come from participants of the Bambuí Cohort Study of Aging, a population-based prospective cohort of older adults carried out in Bambuí, a city of 15,000 inhabitants in the state of Minas Gerais, Southeast Brazil. The cohort procedures have been described in detail elsewhere 16,17. Briefly, the baseline cohort population comprised all residents aged 60 and over on 1 January 1997; 1,606 residents participated out of a total of 1,742 . Baseline data collection was performed from February to May, 1997. Cohort members undergo annual follow-ups, consisting of standardized interviews, selected examinations and verification of death certificates. Functional dependence is one of the main outcome variables. The response rate was high at baseline (92.2\%) and the attrition rate was very small during 10 year follow-up (6.8\%) 16,17 . All participants aged 71-81 years at baseline in 1997 (that is, born from 1916 to 1926) and in 2008 (that is, born from 1927 to 1937) were selected for the present analysis. The Bambuí cohort study was approved by the Ethics Research Committee of the Oswaldo Cruz Foundation (Fundação Oswaldo Cruz), Brazil.

\section{Measurements}

The physical functioning measures included the following self-reported measures: difficulties in performing ADLs 18 , the IADLs 19 and mobility. Participants were asked whether they experienced difficulties with any of the following ADLs: dressing, including putting on shoes and socks; walking across a room; bathing or showering; eating; getting in or out of bed; and using the toilet, including getting up or down. Cohort members were also asked whether they experienced difficulties with any of the following IADLs: preparing a hot meal, managing money and shopping. Mobility questions referred to any difficulty in getting up from a chair; walking 100 yards; climbing stairs; stooping, kneeling and crouching; and lifting or carrying weights. From answers to these questions variables were derived to count the number of difficulties with ADLs, IADLs and 
mobility which were then dichotomized, and participants reporting one or more problems were classified as having impaired physical function.

\section{Statistical analyses}

The univariate analysis of the association between cohort year (the exposure variable) and the physical functioning variables was based on the Pearson's chi square test, for differences between frequencies. In addition, prevalence ratios and their robust $95 \%$ confidence interval (95\%CI) rates for the relationship between the cohort year and physical functioning were obtained using poisson regression and robust $95 \% \mathrm{CI}$. The models were adjusted for sex. Separate analyses were also performed for men and women because the prevalence of physical functioning varied by gender. The Stata software package version 11.0 (Stata Corp., College Station, USA) was used for all analyses.

\section{Results}

At baseline, from a total of 492 participants aged 71-81, 491 had data on physical functioning and were included in the present analyses. Among the 657 cohort members aged 71-81 who took part in the $11^{\text {th }}$ wave of the cohort (2008), 620 (94.4\%) had data on physical functioning levels. The excluded and eligible participants were similar according to gender $(p=0,075)$ and age ( $\mathrm{p}=0,112$ ). Thus, in the present analyses, 491 participants $(44 \%)$ took part in the old cohort (1997) and 620 (56\%) were from the young cohort (2008).

Table 1 displays the association between cohort year and physical functioning. Participants of the young cohort reported significantly less physical functioning difficulties regarding mobility, IADLs and two of the ADLs: getting in or out of bed, eating and dressing. For the ADL eating activity, both cohorts showed similar levels of difficulties. For the remaining ADL: walking across a room, showering and using the toilet, there was an increase in the difficulty levels for these activities in the young cohort (2008).

Table 2 shows the comparisons between the cohort years and physical functioning by sex. Regarding mobility, men from the younger cohort (2008) reported significantly less difficulties than men from the older cohort. A similar pattern was observed regarding the IADLs with the exception of managing money. For the ADL, there was a reduction in the levels of difficulties among men from the young cohort in relation to getting in or out bed and dressing. On the other hand, the remaining $\mathrm{ADL}$ had an increase in the levels of difficulties among men in 2008. However, these differences between the cohort years according to ADLs were not statistically significant.

The results of the relationship between cohort year and physical functioning among women are presented in Table 3. A similar trend to men was observed in terms of mobility tasks. For the ADLs, women from the younger cohort showed an improvement in eating compared to men. They also showed an increase in difficulty for preparing a hot meal (IADLs) compared to men.

The prevalence ratios and their 95\%CI for physical functioning levels among men and women by cohort birth are presented in Table 4 . The general trend observed is an improvement in physical functioning levels among men and women according to mobility tasks and IADLs. For the ADLs, some activities have showed a decline while others improvement.

The association between cohort year and the number of affected physical functioning activities is presented in Table 5. Participants from the younger cohort (2008) reported significantly fewer affected physical functioning activities according to all three measures used.

\section{Discussion}

The main findings from this study showed that physical functioning levels, measured by ADLs, IADLs and mobility were, overall, better among the participants born between 1927 and 1937 compared with those born between 1916 and 1926.

Our findings are in line with some existing longitudinal studies based on national samples. A prospective study in a younger population of Finnish men and women showed results congruent with those of the present study. This study measured self-reported physical functioning according to ADLs, IADLs and mobility tasks and found a gradual improvement in functioning among participants from the younger cohort. A secular trend toward a less disabled and healthier population has also been reported in US populations aged 65 and over by Manton et al. 20 and 55-70 years by Seeman et al 21. Manton et al. 20 further showed that the reduction in disability over time, which had already been seen a decade earlier, had accelerated from the 1980s to the 1990s. On the other hand, the findings from the $4^{\text {th }}$ wave of the English Longitudinal Study of Ageing (ELSA), in relation to the broad questions of trends in levels of disability over time and across birth cohorts, strongly indicate that levels of disability have been stable 22 . 
Physical functioning levels by birth cohort. The Bambuí Cohort Study of Aging, 1997-2008.

\begin{tabular}{|c|c|c|c|}
\hline Physical functioning & $\begin{array}{l}\text { Old cohort } 1997 \\
\qquad(n=491) \\
\%\end{array}$ & $\begin{array}{l}\text { Young cohort } 2008 \\
\qquad \begin{array}{c}(n=620) \\
\%\end{array}\end{array}$ & $\mathrm{p}$-value * \\
\hline \multicolumn{4}{|l|}{ ADL } \\
\hline \multicolumn{4}{|c|}{ Walking across a room } \\
\hline No difficulty & 97.13 & 94.52 & 0.034 \\
\hline Difficulty & 2.87 & 5.48 & \\
\hline \multicolumn{4}{|c|}{ Getting in or out of bed } \\
\hline No difficulty & 90.59 & 93.55 & 0.068 \\
\hline Difficulty & 9.41 & 6.45 & \\
\hline \multicolumn{4}{|l|}{ Eating } \\
\hline No difficulty & 96.93 & 96.61 & 0.766 \\
\hline Difficulty & 3.07 & 3.39 & \\
\hline \multicolumn{4}{|l|}{ Dressing } \\
\hline No difficulty & 89.98 & 91.45 & 0.400 \\
\hline Difficulty & 10.02 & 8.55 & \\
\hline \multicolumn{4}{|l|}{ Showering } \\
\hline No difficulty & 95.08 & 92.90 & 0.134 \\
\hline Difficulty & 4.92 & 7.10 & \\
\hline \multicolumn{4}{|l|}{ Using the toilet } \\
\hline No difficulty & 97.13 & 94.03 & 0.015 \\
\hline Difficulty & 2.87 & 5.97 & \\
\hline \multicolumn{4}{|l|}{ Mobility tasks } \\
\hline \multicolumn{4}{|c|}{ Getting up from a chair } \\
\hline No difficulty & 86.89 & 91.61 & 0.011 \\
\hline Difficulty & 13.11 & 8.39 & \\
\hline \multicolumn{4}{|l|}{ Walking 100 yards } \\
\hline No difficulty & 77.51 & 82.74 & 0.029 \\
\hline Difficulty & 22.49 & 17.26 & \\
\hline \multicolumn{4}{|l|}{ Climbing stairs } \\
\hline No difficulty & 73.62 & 80.97 & 0.003 \\
\hline Difficulty & 26.38 & 19.03 & \\
\hline \multicolumn{4}{|c|}{ Stooping, kneeling and crouching } \\
\hline No difficulty & 62.78 & 69.19 & 0.025 \\
\hline Difficulty & 37.22 & 30.81 & \\
\hline \multicolumn{4}{|c|}{ Lifting or carrying weights } \\
\hline No difficulty & 71.98 & 83.39 & 0.000 \\
\hline Difficulty & 28.02 & 16.61 & \\
\hline \multicolumn{4}{|l|}{ IADL } \\
\hline \multicolumn{4}{|l|}{ Preparing a hot meal } \\
\hline No difficulty & 85.89 & 87.58 & 0.408 \\
\hline Difficulty & 14.11 & 12.42 & \\
\hline \multicolumn{4}{|l|}{ Managing money } \\
\hline No difficulty & 90.39 & 91.45 & 0.539 \\
\hline Difficulty & 9.61 & 8.55 & \\
\hline \multicolumn{4}{|l|}{ Shopping } \\
\hline No difficulty & 69.33 & 77.42 & 0.002 \\
\hline Difficulty & 30.67 & 22.58 & \\
\hline
\end{tabular}

ADL: activities of daily living; IADL: instrumental activities of daily living.

* Pearson's chi square test for differences between frequencies. 
Physical functioning levels among men by birth cohort. The Bambuí Cohort Study of Aging, 1997-2008.

\begin{tabular}{|c|c|c|c|}
\hline Physical functioning & $\begin{array}{l}\text { Old cohort } 1997 \\
\qquad \begin{array}{c}(n=491) \\
\%\end{array}\end{array}$ & $\begin{array}{l}\text { Young cohort } 2008 \\
\qquad \begin{array}{c}(n=620) \\
\%\end{array}\end{array}$ & p-value * \\
\hline \multicolumn{4}{|l|}{ ADL } \\
\hline \multicolumn{4}{|c|}{ Walking across a room } \\
\hline No difficulty & 96.92 & 95.45 & 0.43 \\
\hline Difficulty & 3.08 & 4.55 & \\
\hline \multicolumn{4}{|c|}{ Getting in or out of bed } \\
\hline No difficulty & 91.28 & 93.64 & 0.36 \\
\hline Difficulty & 8.72 & 6.36 & \\
\hline \multicolumn{4}{|l|}{ Eating } \\
\hline No difficulty & 96.92 & 95.45 & 0.43 \\
\hline Difficulty & 3.08 & 4.55 & \\
\hline \multicolumn{4}{|l|}{ Dressing } \\
\hline No difficulty & 88.21 & 90.91 & 0.37 \\
\hline Difficulty & 11.79 & 9.09 & \\
\hline \multicolumn{4}{|l|}{ Showering } \\
\hline No difficulty & 95.38 & 92.27 & 0.19 \\
\hline Difficulty & 4.62 & 7.73 & \\
\hline \multicolumn{4}{|l|}{ Using the toilet } \\
\hline No difficulty & 96.92 & 93.18 & 0.08 \\
\hline Difficulty & 3.08 & 6.82 & \\
\hline \multicolumn{4}{|l|}{ Mobility tasks } \\
\hline \multicolumn{4}{|c|}{ Getting up from a chair } \\
\hline No difficulty & 86.60 & 92.27 & 0.05 \\
\hline Difficulty & 13.40 & 7.73 & \\
\hline \multicolumn{4}{|l|}{ Walking 100 yards } \\
\hline No difficulty & 81.54 & 90.00 & 0.01 \\
\hline Difficulty & 18.46 & 10.00 & \\
\hline \multicolumn{4}{|l|}{ Climbing stairs } \\
\hline No difficulty & 77.95 & 87.27 & 0.01 \\
\hline Difficulty & 22.05 & 12.73 & \\
\hline \multicolumn{4}{|c|}{ Stooping, kneeling and crouching } \\
\hline No difficulty & 70.26 & 79.09 & 0.03 \\
\hline Difficulty & 29.74 & 20.91 & \\
\hline \multicolumn{4}{|c|}{ lifting or carrying weights } \\
\hline No difficulty & 82.56 & 91.36 & 0.01 \\
\hline Difficulty & 17.44 & 8.64 & \\
\hline \multicolumn{4}{|l|}{ IADL } \\
\hline \multicolumn{4}{|l|}{ Preparing a hot meal } \\
\hline No difficulty & 81.03 & 86.36 & 0.14 \\
\hline Difficulty & 18.97 & 13.64 & \\
\hline \multicolumn{4}{|l|}{ Managing money } \\
\hline No difficulty & 93.85 & 93.18 & 0.78 \\
\hline Difficulty & 6.15 & 6.82 & \\
\hline \multicolumn{4}{|l|}{ Shopping } \\
\hline No difficulty & 82.56 & 85.91 & 0.34 \\
\hline Difficulty & 17.44 & 14.09 & \\
\hline
\end{tabular}

ADL: activities of daily living; IADL: instrumental activities of daily living.

* Pearson's chi square test for differences between frequencies. 
Physical functioning levels among women by birth cohort. The Bambui Cohort Study of Aging, 1997-2008.

\begin{tabular}{|c|c|c|c|}
\hline Physical Functioning & $\begin{array}{l}\text { Old cohort } 1997 \\
\qquad \begin{array}{c}(n=491) \\
\%\end{array}\end{array}$ & $\begin{array}{l}\text { Young cohort } 2008 \\
\qquad \begin{array}{c}(n=620) \\
\%\end{array}\end{array}$ & $\mathrm{p}$-value * \\
\hline \multicolumn{4}{|l|}{$A D L$} \\
\hline \multicolumn{4}{|c|}{ Walking across a room } \\
\hline No difficulty & 97.27 & 94.00 & 0.04 \\
\hline Difficulty & 2.73 & 6.00 & \\
\hline \multicolumn{4}{|c|}{ Getting in or out of bed } \\
\hline No difficulty & 90.14 & 93.50 & 0.11 \\
\hline Difficulty & 9.86 & 6.50 & \\
\hline \multicolumn{4}{|l|}{ Eating } \\
\hline No difficulty & 96.94 & 97.25 & 0.81 \\
\hline Difficulty & 3.06 & 2.75 & \\
\hline \multicolumn{4}{|l|}{ Dressing } \\
\hline No difficulty & 91.16 & 91.75 & 0.78 \\
\hline Difficulty & 8.84 & 8.25 & \\
\hline \multicolumn{4}{|l|}{ Showering } \\
\hline No difficulty & 94.88 & 93.25 & 0.37 \\
\hline Difficulty & 5.12 & 6.75 & \\
\hline \multicolumn{4}{|l|}{ Using the toilet } \\
\hline No difficulty & 97.27 & 94.50 & 0.08 \\
\hline Difficulty & 2.73 & 5.50 & \\
\hline \multicolumn{4}{|l|}{ Mobility tasks } \\
\hline \multicolumn{4}{|c|}{ Getting up from a chair } \\
\hline No difficulty & 87.07 & 91.25 & 0.08 \\
\hline Difficulty & 12.93 & 8.75 & \\
\hline \multicolumn{4}{|l|}{ Walking 100 yards } \\
\hline No difficulty & 74.83 & 78.75 & 0.22 \\
\hline Difficulty & 25.17 & 21.25 & \\
\hline \multicolumn{4}{|l|}{ Climbing stairs } \\
\hline No difficulty & 70.75 & 77.50 & 0.04 \\
\hline Difficulty & 29.25 & 22.50 & \\
\hline \multicolumn{4}{|c|}{ Stooping, kneeling and crouching } \\
\hline No difficulty & 57.82 & 63.75 & 0.11 \\
\hline Difficulty & 42.18 & 36.25 & \\
\hline \multicolumn{4}{|c|}{ Lifting or carrying weights } \\
\hline No difficulty & 64.97 & 79.00 & 0.001 \\
\hline Difficulty & 35.03 & 21.00 & \\
\hline \multicolumn{4}{|l|}{ IADL } \\
\hline \multicolumn{4}{|l|}{ Preparing a hot meal } \\
\hline No difficulty & 89.12 & 88.25 & 0.72 \\
\hline Difficulty & 10.88 & 11.75 & \\
\hline \multicolumn{4}{|l|}{ Managing money } \\
\hline No difficulty & 88.10 & 90.50 & 0.31 \\
\hline Difficulty & 11.90 & 9.50 & \\
\hline \multicolumn{4}{|l|}{ Shopping } \\
\hline No difficulty & 60.54 & 72.75 & 0.001 \\
\hline Difficulty & 39.46 & 27.25 & \\
\hline
\end{tabular}

ADL: activities of daily living; IADL: instrumental activities of daily living.

* Pearson's chi square test for differences between frequencies. 
Sex adjusted prevalence ratios (PR) of physical functioning among men and women by birth cohort. The Bambui Cohort Study of Aging, 1997-2008.

\begin{tabular}{|c|c|c|}
\hline \multirow[t]{3}{*}{ Physical functioning } & \multicolumn{2}{|c|}{ Young (2008) vs. old (1997) cohort } \\
\hline & Men & Women \\
\hline & PR $(95 \% \mathrm{Cl})$ & PR $(95 \% \mathrm{Cl})$ \\
\hline \multicolumn{3}{|l|}{ ADL } \\
\hline Walking across a room & $1.48(0.54-3.99)$ & $2.20(1.00-4.82)$ \\
\hline Getting in or out of bed & $0.73(0.37-1.44)$ & $0.66(0.40-1.10)$ \\
\hline Eating & $1.48(0.54-3.99)$ & $0.89(0.38-2.14)$ \\
\hline Dressing & $0.77(0.44-1.36)$ & $0.93(0.57-1.53)$ \\
\hline Showering & $1.67(0.76-3.67)$ & $1.32(0.71-2.43)$ \\
\hline Using the toilet & $2.22(0.88-5.60)$ & $2.01(0.91-4.46)$ \\
\hline \multicolumn{3}{|l|}{ Mobility tasks } \\
\hline Getting up from a chair & $0.58(0.32-1.03)$ & $0.68(0.44-1.04)$ \\
\hline Walking 100 yards & $0.54(0.33-0.89)$ & $0.84(0.64-1.11)$ \\
\hline Climbing stairs & $0.57(0.37-0.89)$ & $0.77(0.60-0.99)$ \\
\hline Stooping, kneeling and crouching & $0.70(0.50-0.98)$ & $0.86(0.71-1.04)$ \\
\hline Lifting or carrying weights & $0.49(0.29-0.84)$ & $0.60(0.47-0.77)$ \\
\hline \multicolumn{3}{|l|}{ IADL } \\
\hline Preparing a hot meal & $0.72(0.46-1.12)$ & $1.08(0.71-1.65)$ \\
\hline Managing money & $1.11(0.53-2.31)$ & $0.80(0.52-1.23)$ \\
\hline Shopping & $0.81(0.52-1.26)$ & $0.70(0.56-0.86)$ \\
\hline
\end{tabular}

ADL: activities of daily living; IADL: instrumental activities of daily living; $95 \% \mathrm{Cl}$ : $95 \%$ confidence interval.

Note: the figures highlighted in bold are statistically significant.

\section{Table 5}

Sex adjusted prevalence ratios (PR) of the number of affected physical functioning activities by birth cohort. The Bambui Cohort Study of Aging, 1997-2008.

\begin{tabular}{|c|c|c|c|}
\hline Physical functioning & $\begin{array}{l}\text { Old cohort } 1997 \\
\qquad \begin{array}{c}(n=491) \\
\%\end{array}\end{array}$ & $\begin{array}{l}\text { Young cohort } 2008 \\
\qquad(n=620) \\
\%\end{array}$ & $\begin{array}{l}\text { Young (2008) vs. old } \\
\text { (1997) cohort } \\
\text { PR }(95 \% \mathrm{Cl})\end{array}$ \\
\hline \multicolumn{4}{|c|}{ Number of affected ADL } \\
\hline None & 84.84 & 90.47 & $0.65(0.46-0.91)$ \\
\hline 1 & 6.76 & 3.78 & \\
\hline 2 or more & 8.40 & 5.76 & \\
\hline \multicolumn{4}{|c|}{ Number of affected mobility tasks } \\
\hline None & 56.85 & 69.96 & $0.62(0.52-0.74)$ \\
\hline 1 & 16.16 & 15.83 & \\
\hline 2 or more & 26.99 & 14.21 & \\
\hline \multicolumn{4}{|c|}{ Number of affected IADL } \\
\hline None & 64.01 & 86.15 & $0.45(0.35-0.58)$ \\
\hline 1 & 24.13 & 5.76 & \\
\hline 2 or more & 11.86 & 8.09 & \\
\hline
\end{tabular}

ADL: activities of daily living; IADL: instrumental activities of daily living; $95 \% \mathrm{Cl}$ : $95 \%$ confidence interval.

Note: the figures highlighted in bold are statistically significant.

There is some evidence showing gender differences in relation to physical functioning among elderly persons. Compared with men, women report greater difficulty with physical function and less recovery from disability 23 . In the present study, women had higher levels of difficulty ac- 
cording to mobility tasks and IADLs than men. On the other hand, the present findings also showed that men and women have similar levels of physical difficulty according to the ADLs. Surveys have reported that declines in functional limitations occurred only among women 24 or were larger among women than men 25 , whereas others note that disability declines were about the same among women and men 26 . Thus, it remains unclear if the disability gaps between men and women have narrowed or remained stable over time. Overall, although women live longer than men, they do not always report better health indicators. Women are more likely to report more physical functioning than men. For example, in 2003, in Brazil, $17.6 \%$ of elderly men reported levels of difficulty in walking 100 meters compared to $26.6 \%$ for women. Some studies, however, showed that women do not develop more physical function than men, but live longer with their physical limitations. Such a fact could be explained, at least partly, due to differences in diseases affecting men and women reporting physical limitations and also behavioural differences with women seeking more health services than men, indicating a higher level of knowledge about health among women.

The causes for the improved disability trends are not well understood. A possible explanation is the "compression of morbidity" hypothesis, whereby disease and disability are postponed until the end of the lifespan 27 . The improvement in physical functioning levels experienced by the younger cohort in the present study could be due to improvements in access to health care with changes in socioeconomic factors. Other factors, such as improvements in educational levels and innovations in diagnosis and treatment of chronic illness, improvements in health-related behaviours, especially smoking cessation, better diet and increased physical activity, and the emergence of alternative living arrangements and expanded use of assistive devices allowing older persons to maintain independence should also be considered 28 .

Between 1997 and 2008 important differences among cohort members were observed. One of the differences was an increase in the use of medication by the participants born between 1927 and 1937 compared to those born between 1916 and 1926, especially regarding the use of drugs for the treatment of hypertension, diabetes and hyperdyslipidemia 29,30. The young cohort had lower levels of smoking, lower mean total cholesterol and lower mean diastolic blood pressure. On the other hand, in the same cohort, there was an increase in the prevalence of both hypertension and diabetes. They also showed higher mean systolic blood pressure and increased body mass index 29,31. These changes could potentially explain the differences observed in physical functioning levels between the two cohorts. However, only longitudinal analyses will allow us to draw more conclusive results.

There are several important strengths of this study such as its population-based nature, high response rates at both baseline and at the $11^{\text {th }}$ wave of the cohort, the use of the same measures in both times and the long period between the two comparisons (10 years). A potential limitation of our study is survival bias. Poor physical functioning is a stronger predictor of mortality among the Bambuí cohort members 16. Other populationbased cohort studies have also reported increased risks of mortality associated with the inability of elderly persons to complete ADLs and/or IADLs $32,33,34$. However, it is not reasonable to assume that the mortality rate was higher in the young cohort compared to the old one. Therefore, it is unlikely that selective mortality had affected differently the two studied cohorts. Self reporting is another possible source of bias. In the oldest group, self reported measures may give a more optimistic view of the physical abilities than performance based measures ${ }^{35}$. Some studies have shown a strong correlation between subjective and objective measures of physical functioning 36 whereas others have found the association to be much lower. However, subjective and objective measures capture physical abilities differently: the performance indices may be seen as indicators of functional limitations at a given point in time whereas self reported ADL reflects experienced disability over at least a slightly longer period of time and, thus, the ability of a person to live independently in their own home, whether relying on various aids or equipment or without any aid. This potential source of bias is unlikely to have affected the present findings since participants from both cohorts had the same age.

In conclusion, the findings from the present study showed that there are cohort differences in physical functioning levels among the oldest group of participants from the Bambuí Cohort Study of Aging. The younger cohort (2008) had better levels. The reasons for such differences still need to be fully established. Further research is needed, based on longitudinal analyses, for a better understanding of the underlying mechanisms contributing to functional trajectories in this and other elderly populations in middle and low income countries. 


\section{Resumo}

Foram examinadas diferenças de coorte (entre nascidos em 1916-1926 e em 1927-1937) em relação aos níveis de capacidade física entre idosos participantes da coorte sobre o envelhecimento de base populacional de Bambuí, Minas Gerais, Brasil. Foram utilizados dados dos participantes com 71-81 anos de idade da linha de base $(n=491)$ e do 11 o ano de seguimento $(n=620)$. As seguintes medidas autorreferidas de capacidade fisica foram analisadas: atividades da vida diária, atividades instrumentais da vida diária e mobilidade. Regressão de Poisson foi empregada para investigar as diferenças de prevalência da capacidade física entre as duas coortes. De um modo geral, a coorte mais jovem (2008) apresentou melhores níveis de capacidade física do que a coorte mais antiga (1997) com relação às três medidas utilizadas.

Idoso; Atividades Cotidianas; Envelhecimento; Estudos de Coortes

\section{Contributors}

C. M. Oliveira contributed to the conception and design, data analysis, interpretation of data and writing of the manuscript. M. F. Lima-Costa contributed to the conception and design, data collection, data analyses and critical revision. Both authors approved the final version.

\section{Acknowledgments}

To FINEP, CNPq and FAPEMIG for their financial support.

\section{References}

1. Lima-Costa MF, Peixoto SV, Giatti L. Tendências da mortalidade entre idosos brasileiros. Epidemiol Serv Saúde 2004; 13:217-28.

2. Fries JF. Medical perspectives upon successful ageing. In: Baltes PB, Baltes MM, editors. Successful ageing, perspectives from the behavioral sciences. Cambridge: Cambridge University Press; 1993. p. 35-49.

3. Scott WK, Macera CA, Cornman CB, Sharp PA. Functional health status as a predictor of mortality in men and women over 65. J Clin Epidemiol 1997; 50:291-6.

4. Ganguli M, Dodge HH, Mulsant BH. Rates and predictors of mortality in an ageing, rural, community-based cohort: the role of depression. Arch Gen Psychiatry 2002; 59:1046-52.
5. Korten AE, Jorm AF, Jiao Z, Letenneur L, Jacomb PA, Henderson AS, et al. Health, cognitive, and psychosocial factors as predictors of mortality in an elderly community sample. J Epidemiol Community Health 1999; 53:83-8.

6. Bernard SL, Kincade JE, Konrad TR, Arcury TA, Rabiner DJ, Woomert A, et al. Predicting mortality from community surveys of older adults: the importance of self-rated functional ability. J Gerontol B Psychol Sci Soc Sci 1997; 52:S155-63.

7. Melzer D, McWilliams B, Brayne C, Johnson T, Bond J. Profile of disability in elderly people: estimates from a longitudinal population study. BMJ 1999; 318:1108-11.

8. Fried LP, Guralnik JM. Disability in older adults: evidence regarding significance, etiology, and risk. J Am Geriatr Soc 1997; 45:92-100. 
9. World Health Organization. The international classification of functioning, disability and health ICF. Geneva: World Health Organisation; 2001.

10. Studenski S, Perera S, Wallace D, Chandler JM, Duncan PW, Rooney E, et al. Physical performance measures in the clinical setting. J Am Geriatr Soc 2003; 51:314-22.

11. Okoro CA, Zhong Y, Ford ES, Balluz LS, Strine TW, Mokdad AH. Association between the metabolic syndrome and its components and gait speed among U.S. adults aged 50 years and older: a crosssectional analysis. BMC Public Health 2006; 6:282.

12. Garman KS, Cohen HJ. Functional status and the elderly cancer patient. Crit Rev Oncol Hematol 2002; 43:191-208.

13. Freedman VA, Martin LG, Schoeni RF. Recent trends in disability and functioning among older adults in the United States. JAMA 2002; 288: 3137-46.

14. Lafortune G, Balestat G; Disability Study Expert Group Members. Trends in severe disability among elderly people: assessing the evidence in 12 OECD countries and the future implications. Paris: Organisation de Coopération et de Développement Economiques; 2007. (OECD Health Working Papers).

15. Lima-Costa MF, Matos DL, Camargos VO, Macinko J. Tendências em dez anos das condições de saúde de idosos brasileiros: evidências da Pesquisa Nacional por Amostra de Domicílios (1998, 2003, 2008). Ciênc Saúde Coletiva; in press.

16 Lima-Costa MF, Peixoto SV, Matos DL, Firmo JOA, Uchôa E. Predictors of 10-year mortality in a population of community-dwelling Brazilian elderly: the Bambuí Cohort Study of Aging. Cad Saúde Pública 2011; 27 Suppl 3:S360-9.

17. Lima-Costa MF, Firmo JOA, Uchôa E. Cohort profile: the Bambui (Brazil) Cohort Study of Aging. Int J Epidemiol 2010; [Epub ahead of print].

18. Katz S, Ford AB, Moskowitz RW, Jackson BA, Jaffe MW. Studies of illness in the age. The index of ADL: a standardized measure of biological and psychological function. JAMA 1963; 185:914-9.

19. Lawton MP, Brody EM. Assessment of older people: self-maintaining and instrumental activities of daily living. Gerontologist 1969; 9:179-86.

20. Manton KG, Gu X, Lamb VL. Change in chronic disability from 1982 to $2004 / 2005$ as measured by long-term changes in function and health in the U.S. elderly population. Proc Natl Acad Sci USA 2006; 103:18374-9.

21. Seeman TE, Merkin SS, Crimmins EM, Karlamangla AS. Disability trends among older Americans: National Health and Nutrition Examination Surveys, 1988-1994 and 1999-2004. Am J Public Health 2010; 100:100-7.

22. Zaninotto P, Nazroo J, Banks J. Trends in disability. In: Banks J, Lessof C, Nazroo J, Rogers N, Stafford M, Steptoe A, editors. Financial circumstances, health and well-being of the older population in England: the 2008 English Longitudinal Study of Ageing. London: Institute for Fiscal Studies; 2010. p. $254-74$
23. Beckett LA, Brock DB, Lemke JH. Analysis of change in self-reported physical function among older persons in four population studies. Am J Epidemiol 1996; 143:766-78.

24. Crimmins E, Saito Y. Change in the prevalence of diseases among older Americans: 1984-1994. Demogr Res 2000; (3). http://www.demographic-re search.org/Volumes/Vol3/9/3-9.

25. Freedman VA, Martin LG. Understanding trends in functional limitations among older Americans. Am J Public Health 1998; 88:1457-62.

26. Schoeni RF, Freedman VA, Wallace RB. Persistent, consistent, widespread, and robust? Another look at recent trends in old-age disability. J Gerontol B Psychol Sci Soc Sci 2001; 56:S206-18.

27. Fries JF. Measuring and monitoring success in compressing morbidity. Ann Intern Med 2003; 139:455-9.

28. Murabito JM, Pencina MJ, Zhu L, Kelly-Hayes M, Shrader P, D'Agostino RB Sr. Temporal trends in self-reported functional limitations and physical disability among the community-dwelling elderly population: the Framingham Heart Study. Am J Public Health 2008; 98:1256-62.

29. Freitas MPD, Loyola Filho AI, Lima-Costa MF. Birth cohort differences in cardiovascular risk factors in a Brazilian population of older elderly: the Bambuí Cohort Study of Aging (1997 and 2008). Cad Saúde Pública 2011; 27 Suppl 3:S409-17.

30. Loyola Filho AI, Firmo JOA, Uchôa E, Lima-Costa MF. Birth cohort differences in medication use in a Brazilian population of older elderly: the Bambuí Cohort Study of Aging (1997 and 2008). Cad Saúde Pública 2011; 27 Suppl 3:S435-43.

31. Sales ADF, Cesar CC, Lima-Costa MF, Caiaffa WT. Birth cohort differences in anthropometric measures in the old elderly: the Bambuí Birth cohort Study of Aging (1997 and 2008). Cad Saúde Pública 2011; 27 Suppl 3:S418-26.

32. Ramos LR, Simões EJ, Albert MS. Dependence in activities of daily living and cognitive impairment strongly predicted mortality in older urban residents in Brazil: a 2-year follow-up study. J Am Geriatr Soc 2001; 49:1168-75.

33. Nybo H, Petersen HC, Gaist D, Jeune B, Andersen K, McGue M, et al. Predictors of mortality in 2,249 nonagenarians: the Danish 1905-Cohort Survey. J Am Geriatr Soc 2003; 51:1365-73.

34. Scott WK, Macera CA, Cormman CB, Sharpe PA. Functional health status as a predictor of mortality in men and women over 65. J Clin Epidemiol 1997; 50:291-6.

35. Sinoff G, Ore L. The Barthel activities of daily living index: self-reporting versus actual performance in the old-old ( $>$ or $=75$ years). J Am Geriatr Soc 1997; 45:832-6.

36. Kivinen P, Sulkava R, Halonen P, Nissinen A. Selfreported and performance-based functional status and associated factors among elderly men: the Finnish cohorts of the seven countries study. J Clin Epidemiol 1998; 51:1243-52.

Submitted on $02 / \mathrm{Dec} / 2010$

Final version resubmitted on 29/Mar/2011

Approved on 07/May/2011 